\title{
Conhecimento dos profissionais de saúde sobre a gripe a h1n1 e a vacina
}

\section{Conocimientos de los profesionales sanitarios sobre la gripe h1n1 y la vacuna}

DOI: $10.46814 /$ lajdv3n5-011

Recebimento dos originais: 01/07/2021

Aceitação para publicação: 31/08/2021

\section{Grazielly Mader Almeida}

Formação acadêmica mais alta: Graduada pela

Instituição de atuação atual: Centro Cardiológico Dr Edgard Ferreira de Araújo - Salinas/MG

Endereço: Rua Petrópolis, 55 apto 102 - Bairro Raquel

E-mail: gra.imader@hotmail.com

\section{Gérsica Fayane da Silva Gomes}

Pós-Graduação

Instituição de atuação atual: Unidade de Longa Permanência para Idosos Abrigo Comendador

Walmor

Endereço institucional: R. José Leão Souza Filho, 122 - Jardim Riviera, Aparecida de Goiânia - GO

E-mail: gersica.fellipe@ hotmail.com

\begin{abstract}
RESUMO
Trata-se de um estudo exploratório, de caráter descritivo e com abordagem qualitativa que objetivou analisar o conhecimento dos profissionais de saúde sobre a Gripe A H1N1 e a vacina. Os dados foram obtidos através de uma entrevista semiestruturada, gravada com 13 profissionais de uma Estratégia Saúde da Família, situada ao norte de Minas Gerais e analisados mediante a análise temática de conteúdo. A partir do discurso dos entrevistados emergiram as seguintes categorias: "Conhecimento sobre a Influenza A H1N1"; "Meios de prevenção"; "Mitos sobre a vacina e sobre a doença" e "Obtenção de informações". Observou-se que os enfermeiros possuem conhecimento mais estabelecido em relação às outras categorias de profissionais. Os técnicos em enfermagem e agentes comunitários de saúde (ACS) demonstraram através dos relatos pouca ou nenhuma informação sobre a Gripe A H1N1 e a vacina. Os ACS têm um maior vínculo com a população e fazem referência a existência de mitos sobre a vacina e acreditam que os efeitos colaterais são a principal justificativa para a não adesão à vacina.Ocorre confusão da Gripe A H1N1 com outras doenças. A principal fonte de informações para os enfermeiros é o Ministério da Saúde e para técnicos e ACS são televisão, os enfermeiros da unidade e o convívio social. A educação permanente se constitui uma ferramenta para o enfermeiro no sentido transmitir informações básicas relacionadas à Influenza A (H1N1) aos profissionais que não compreendem corretamente as orientações preconizadas pelo Ministério da Saúde.
\end{abstract}

Palavras Chave: Vírus da influenza A subtipo H1N1, Programa Saúde da Família, Vacinação, conhecimento.

\section{ABSTRACT}

This is an exploratory, descriptive and qualitative approach aimed at analyzing the knowledge of health professionals about the H1N1 flu and vaccine. Data were collected through a semi-structured interview, recorded with 13 professionals from a Family Health Strategy, situated north of Minas Gerais and analyzed by thematic content analysis. From the speech of the respondents the following categories emerged: "Knowledge about the Influenza A H1N1" "Means of prevention", "Myths about the vaccine and the disease" and "Getting information". It was observed that the category of nurses have greater knowledge in relation to other categories of professionals. The nursing technicians and community health agents (CHA) demonstrated through reports little or no information about the H1N1 flu and vaccine. The ACS have a stronger connection with the community and refers to the existence of myths about the vaccine and believe that the side effects of the main reasons for non-adherence to the vaccine. The main source of information for nurses is the Ministry of Health for technical and ACS are television, nurses and social life of the unit. Continuing education constitutes a 
powerful tool for nurses in order to transmit the basic information related to Influenza A (H1N1) to professionals who misunderstand the guidelines recommended by the Ministry of Health.

Keywords: Influenza A Virus, H1N1 Subtype, Family Health Program, Vaccination, Knowledge.

\section{INTRODUÇÃO}

A Gripe A é uma doença viral aguda do sistema respiratório, contagiosa e com alto poder de transmissibilidade, causada pelo vírus Influenza A (H1N1), que foi descoberto em abril de 2009 no México em meio a uma epidemia. Logo que surgiu se espalhou rapidamente pelo mundo. Em seu primeiro ano de circulação o vírus provocou cerca de 12.800 óbitos, sendo no Brasil 2.051 óbitos e mais de 44 mil casos confirmados da doença (PASTORE; PRATES; GUTIERREZ, 2012).

O vírus é classificado como da família Orthomyxoviridae, formado por estrutura de RNA simples, variando entre subtipos classificados como A, B e C. Causando graves complicações respiratórias, os tipos B e C são responsáveis por acometer humanos e o tipo A por infectar ampla variação de animais (OLIVEIRA; IGUTI, 2010).

As manifestações clínicas da gripe causada pelo vírus influenza A H1N1 são, em geral, semelhantes aos verificados na influenza sazonal humana (gripe comum), destacando-se a possibilidade de náuseas, vômitos e diarréia, sendo que, na maioria das vezes o quadro é autolimitado, requerendo apenas cuidados e medidas de suporte gerais. Contudo, em alguns casos a infecção causada pelo vírus influenza A H1N1 pode se manifestar de forma mais grave, podendo levar o paciente a um quadro de insuficiência respiratória e a óbito (SENNA et al,. 2009).

Dados do Ministério da Saúde demonstram, que de uma forma geral houve uma redução no número de casos confirmados a partir do final do mês de março de 2010, queda possivelmente associada com as campanhas de prevenção. Desde o princípio da pandemia, as medidas de prevenção foram amplamente divulgadas, como lavar as mãos frequentemente, usar álcool gel a $70 \%$ para desinfecção das mãos, evitar ambientes fechados e aglomerações, usar lenços descartáveis ao tossir e espirrar, não compartilhar utensílios como talheres e copos (BRASIL, 2010).

O controle da disseminação pela vacina específica também se constitui em uma medida eficaz para reduzir a morbimortalidade pelo vírus $\mathrm{H} 1 \mathrm{~N} 1$, pois confere proteção acima de $80 \%$ em indivíduos com imunidade normal. Nos indivíduos com imunidade diminuída, a vacina possui eficácia menor, contudo, diminui as chances de infecções secundárias e complicações. A vacina pode ser administrada em dose única ou múltiplas doses. As prioridades na estratégia de vacinação são os trabalhadores de saúde, população indígena, gestantes em qualquer idade gestacional, crianças com idade superior a seis 
meses e inferior a dois anos de idade, portadores de doenças crônicas, adultos de 20 a 39 anos pessoas com idade superior a 60 anos (MINISTERIO DA SAÚDE, 2010).

A Atenção Primária à Saúde (APS), sobretudo as equipes de Saúde da Família (ESF), constituem porta de entrada preferencial do sistema de saúde e tem por objetivo a promoção de saúde e prevenção de agravos. A ESF possui um vínculo estreito com a comunidade em que estão inseridas e devem aproveitar os espaços das visitas domiciliares e grupos educativos para fazer educação em saúde e esclarecer a população sobre vários assuntos relacionados à influenza H1N1 (BRASIL, 2011).

Diante do exposto, é fundamental que a equipe da ESF possua conhecimento adequado sobre a Influenza A H1N1, com vistas a esclarecer possíveis equívocos que a população possa ter em relação à doença, alertando a comunidade para a situação de vigilância sem, contudo, banalizar ou superestimar. Além disso, a população bem informada é fundamental no enfrentamento da disseminação da gripe por Influenza A H1N1.

Frente a esta realidade, o objetivo deste trabalho é analisar o conhecimento dos profissionais de saúde sobre a Gripe A H1N1 e a vacina.

\section{METODOLOGIA}

Trata-se de um estudo descritivo, com abordagem qualitativa. A pesquisa qualitativa se preocupa com uma realidade que não ser quantificada, ela trabalha com o universo de significados, motivos, aspirações, crenças, valores e atitudes (MINAYO, 2007).

O estudo foi realizado na área de abrangência de uma equipe da Estratégia de Saúde da Família do município de Novorizonte, Minas Gerais, situada ao norte do estado. O município possui aproximadamente 4.693 habitantes, e conta atualmente com duas equipes de ESF que atendem toda a cidade e sua comunidade rural.

Participaram do estudo 13 profissionais de saúde da ESF urbana do município de Novorizonte - Minas Gerais. A amostragem por saturação foi utilizada como ferramenta para estabelecer o número de entrevistados, ou seja, foi suspensa a inclusão de novos participantes quando os dados obtidos apresentaram redundância ou repetição, não sendo considerado relevante persistir na coleta de dados (FONTANELLA et al., 2008).

Foram escolhidos para o estudo os indivíduos que atenderam aos seguintes critérios de inclusão: profissionais vinculados e atuantes na ESF pesquisada, que possuam entre 18 e 60 anos, não estar de férias ou atestado, que concordaram em participar da pesquisa.

Os dados foram obtidos por meio de uma entrevista semiestruturada, estabelecida mediante um roteiro. Essa técnica é realizada por meio de um encontro entre duas pessoas em que uma delas busca obter informações sobre determinado assunto, a fim de obter dados que possam ajudar no diagnóstico 
ou no tratamento de um problema social (MARCONI; LAKATOS, 2007). A questão norteadora da entrevista foi: “O que o senhor (a) sabe sobre a gripe A H1N1 e a vacina?". As entrevistas aconteceram na unidade da ESF e tiveram duração média de 10 a 15 minutos. As informações obtidas foram gravadas e, posteriormente, transcritas na íntegra.

Neste estudo foram respeitados todos os princípios éticos em pesquisa com seres humanos. O responsável legal pela instituição autorizou a realização da pesquisada por meio da anuência ao Termo de Concordância Institucional, onde consta a assinatura. Os indivíduos foram cuidadosamente informados sobre os objetivos da pesquisa e em seguida foi apresentado o Termo de Consentimento Livre e Esclarecido para a participação na pesquisa, constando a assinatura do entrevistado. Para garantir o anonimato e a preservação da identidade do entrevistado, foram utilizadas as vogais iniciais de cada categoria pesquisada. Para os enfermeiros, utilizou-se a vogal "E”, para os técnicos em enfermagem a vogal "T" e para os ACS a vogal "A”. O estudo foi submetido ao Comitê de Ética em Pesquisa e aprovado pelo parecer $\mathrm{n}^{\mathrm{o}} 226.720$.

Após a transcrição das entrevistas, foram realizadas repetidas e exaustivas leitura do material para ordenar os dados. A técnica para análise de dados selecionada foi a análise temática de conteúdo que é um meio de expressão do indivíduo, em que se busca categorizar as unidades de texto, palavras ou frases que se repetem, inferindo uma expressão que as representam. A análise foi feita em três fases: pré-análise, exploração do material e tratamento dos resultados. Foi possível desvelar as categorias relevantes e confrontá-las à luz da literatura atual (MINAYO, 2007).

\section{RESULTADOS}

Neste estudo, verificou-se a predominância de profissionais de saúde $(12 ; 91,7 \%)$ do sexo feminino. Os profissionais entrevistados têm em média 27,2 anos. Com relação à escolaridade, 50\% (6 profissionais) possuem ensino médio completo e 3 profissionais $(33,3 \%)$ possuem ensino superior completo. Dois profissionais $(16,7 \%)$ possuem ensino médio incompleto.

Em relação à situação conjugal 5 profissionais $(41,7 \%)$ são casados e $5(41,7 \%)$ são solteiros; dois (16,6\%) vivem em união estável. Quanto à profissão, 3 profissionais entrevistados (23\%) são enfermeiros, 6 (46\%) são Agentes Comunitários de Saúde e 4 (31\%) são técnicos em enfermagem.

A partir da compreensão das entrevistas com os profissionais de saúde, foram identificadas quatro categorias: "Conhecimento sobre a Influenza A H1N1"; "Meios de prevenção"; "Mitos sobre a vacina e sobre a doença" e "Obtenção de informações". 


\title{
3.1 CONHECIMENTO SOBRE A INFLUENZA A H1N1
}

Ao analisar o discurso dos entrevistados percebe-se que a maioria dos entrevistados já ouviu falar sobre a Influenza A H1N1, apenas um entrevistado relatou que não se lembrava de nada sobre a Influenza. No entanto, nenhum deles associou a Influenza A H1N1 como uma doença do sistema respiratório. De acordo com os relatos observa-se que a Influenza A é destacada em sua forma de transmissão:

Eu sei que ela é uma gripe que transmite por contato direto. (T3)

Da Gripe HIN1 eu só sei que é uma doença que é transmissível de uma para outra se não tiver higiene mesmo, que tem que usar álcool gel, mais essas coisas. Que tem que lavar as mãos bem lavadas pra não estar transmitindo de uma pessoa para outra. (A2)

O mais básico é que a Gripe A tinha chegado ao Brasil, tinha causado alguns óbitos, que é uma gripe que passava muito rápido, de uma pessoa para outra, que a contaminação era rápida e a evolução mais rápida ainda (...). (E1)

Sabemos que é um vírus e como todo vírus é transmitido através de vias aéreas, através de contato das mãos com maçaneta de portas, essas coisas. (E2)

A Gripe A se pega através de secreções. (E3)

Segundo os relatos abaixo é possível notar que os entrevistados fazem comparações entre a Gripe A e a gripe comum, enfatizando uma maior agressividade da Gripe A.

\begin{abstract}
Sobre a gripe eu só sei que ela é quase uma gripe normal mesmo, com algumas características mais agressivas do que essa (Influenza B). (A3)

(...) Ela é tipo uma gripe como a outra, assim na forma de transmissão dela (...). (A6)

(...) Eu acho que é uma gripe assim, não é essas "gripinha" normal, comum, é uma gripe que afeta bastante a população e que prejudica bastante por ser uma gripe mais perigosa do que essa comum. (A5)
\end{abstract}

Contudo, nesta categoria, houve alguns entrevistados que possuíam pouco conhecimento sobre a Influenza A H1N1, uns por verbalizarem o fato de não saber, ou não se lembrar e outros por confundirem as informações, como pode ser percebido abaixo:

No momento eu não estou lembrando. (A1)

Eu sei que a doença em si ela causa muito mal estar, ela deixa a pessoa bastante inquieta e na verdade eu não sei por que acontece isso, mas infelizmente é (...) eu tenho pouco conhecimento em relação (A2)

\subsection{MEIOS DE PREVENÇÃO}

Ao analisarmos o nível de conhecimento dos profissionais de saúde sobre os meios de prevenção da Influenza A H1N1 observamos que nem todos os profissionais possuem conhecimento em relação às atitudes preventivas mínimas para evitar o acometimento pelo vírus H1N1 como lavagem das mãos, adotar medidas de higiene, atentar para o cuidado ao tossir e espirrar, não compartilhar 
objetos, manter o ambiente limpo e evitar locais de muita aglomeração. Notou-se o desconhecimento dos profissionais sobre os meios de prevenção. Em algumas falas pode-se observar um conhecimento mais amplo, em que foi citado mais de um meio de prevenção e em outras foi citado apenas um meio de prevenção ou por esquecimento ou por falta de conhecimento mesmo.

\begin{abstract}
Higiene, lavagem das mãos com frequência, uso de álcool gel, manobras para tosse, aquela do cotovelo. (E1)

Lavagem das mãos, evitar ambientes aglomerados (...). (E3)

Higiene. Higiene principalmente. Tem que tá sempre lavando as mãos. E tinha um país aí que eles usavam até uma máscara, assim eu vi no jornal. (A6)

Higiene, cuidado ao espirrar, lavar as mãos, usar álcool gel, pra tá evitando. Evitar pegar em locais que outras pessoas pegaram e sempre lavar as mãos. (A3)

Eu acho que o jeito mais prático é a vacina contra essa gripe, eu acho. Ah eu acho que eu posso tá evitando ficar muito pertinho, ta usando alguma máscara, ou sempre que for pegar em algum local tá sempre lavando as mãos antes e após com álcool. Essas coisas. (A5)

No momento foi só a vacinação mesmo (...) e assim, lavagem das mãos, passar álcool nas mãos, também usou-se muito isso e evitar ambiente muito fechado. (T1)

Quando você for tossir no caso, você tem que tá colocando a mão na boca, estar passando o álcool na mão também, acho que também é bem necessário. E tem a vacina também. (T4)

Tem que tá evitando, é compartilhar copos, talheres (...). Mais era compartilhar, copo, garrafa, que eu me lembro é isso. (T3)
\end{abstract}

Por essas falas também podemos verificar que apenas três dos entrevistados apontam a vacina como um meio de prevenção o que demonstra que os profissionais não conhecem na totalidade os meios de prevenção, uma vez que a vacina é o método mais eficaz na prevenção da doença.

Em algumas falas o conhecimento dos profissionais no que toca os meios de prevenção apresentou-se insatisfatório, com falas fragmentadas, apresentação de conteúdo errôneo e às vezes equivocados, notadamente, quando se associou a doença com picadas de insetos e colocando como meio de prevenção evitar contato com "coisas". Um dos profissionais também relatou não se lembrar de nenhum meio de prevenção.

De prevenir? É tomando bastante líquido. Evitar contatos em lugar onde possa ta acontecendo picada de algum inseto, isso aí (risos). (T2)

Não estou lembrando de nada no momento. (A1)

Assim, evitando contato com as coisas. (A4)

\title{
3.3 MITOS SOBRE A VACINA E SOBRE A DOENÇA
}

No decorrer das entrevistas foi possível observar alguns mitos relacionados à doença, como o fato de alguns associarem a Influenza A H1N1, como a doença do porco ou que a transmissão se dá pela carne do porco. 
Houve também um profissional entrevistado que classificou a Influenza A H1N1 como gripe aviária, conforme descrito abaixo:

Eu acho que a gripe (...) é a gripe aviária. (A5).

No que diz respeito às formas de transmissão, foram relatados informações errôneas, quando os profissionais afirmam que a doença pode ser transmitida por contato com sangue, por picadas de inseto e pela relação sexual.

Evitar contato com saliva, com sangue. (T3)

Pelo vírus de uma pessoa para outra, pela relação (sexual). (A4)

Evitar contatos em lugar, locais onde possa "ta" acontecendo picada de algum inseto, isso aí. (T2)

Obtiveram-se diferentes relatos quanto à disponibilização da vacina para a Gripe H1N1. Contudo, acredita-se que a vacina seja disponibilizada apenas em campanhas anuais.

Foi disponibilizada apenas no período da campanha. (E1)

É disponibilizada sim. (E2)

Olha, o que "nós tá" sabendo agora, inclusive essa campanha que vai ter agora do idoso, essa vacina da H1N1 "tá" incluida, junto com a gripe normal. (T1)

Outra questão abordada foi em relação à vacinação de pessoas alérgicas a ovo. Um entrevistado relatou que a vacina é destinada a pessoas alérgicas a ovo e outro entrevistado diz que a vacina é contra-indicada para pessoas com alergia a ovo.

(...) Eu sei que ela tem o mesmo padrão da outra influenza, que são para pessoas alérgicas a ovo. (E1)

(...) Mas eu acho que ela é feita do conteúdo do ovo da galinha, por que até "eles fala" assim: quem tem alergia à ovo não pode ta tomando. (T1)

Quando perguntados sobre os mitos que permeiam a vacina da Influenza A H1N1, os entrevistados, sobretudo a categoria de Agente Comunitário de Saúde, conhecem usuários que tenham rejeitado a vacina por algum mito. O que fica mais evidente é que as pessoas alegam os efeitos colaterais como o principal fator a não adesão à vacina.

Muitos nem tomou, é porque na minha área lá muitas pessoas nem tomou, porque dá uma reação forte com a vacina e pelo que eu ouvi, muitos desistiu da vacina, porque dá febre alta, dava dor no corpo. (A2)

Tem gente que fala que vacinou, aí teve gripe até pior do que antes e já tem uma resistência e não queria vacinar mais. (A3)

Eu acho que fica com medo assim de levar a vacina e tá fazendo eles ficarem ruim e não querem tomar. (A5) 
Contudo, alguns dos entrevistados referiram desconhecer algum usuário que tenha rejeitado a vacina por algum mito. Apenas um entrevistado relatou que a rejeição não é uma exclusividade da Influenza H1N1.

\author{
Sempre tem alguns que rejeitam. Mais eu nunca ouvi falar não. (T3) \\ Não. Aqui eu nunca ouvi falar de ninguém que recusou alegando algum efeito colateral. (E3) \\ Não nunca ouvi falar não. (T4) \\ Oh, tem muitos tipos de pessoas que não só a Gripe H1N1, elas recusam. Tem essas pessoas, \\ mais que eu já ouvi falar sobre a H1N1, que recusou, não. (A6)
}

Um profissional justificou o fato de acreditar que ninguém recusou a vacina com o fato de a população estar com muito medo e como se tratava de uma vacina nova, não teria motivos para relatar algum efeito colateral.

Até porque na época a gente ficou com muito medo dela. Mais eu acredito que sempre tem, mais como nunca tinha tomado, eu acredito que alegando o motivo do efeito colateral eu acredito que não. Porque nunca tinha tomado, era uma vacina nova. (A6)

\title{
3.4 OBTENÇÃO DE INFORMAÇÕES
}

Quando questionados sobre os meios pelos quais obtiveram informações sobre a Influenza A H1N1 e a vacina, os enfermeiros relataram obtenção das informações através do Ministério da Saúde, por meio da Gerência Regional de Saúde e também por conhecimento de mídia.

Através da Regional de Saúde, na época da movimentação da H1N1 foi feito treinamento no período. (E1)

Através de cartilhas que o Ministério manda e conhecimentos de mídia também. (E2)

Através de oficios da Regional, que foram enviados pra gente. (E3)

Os outros profissionais colocam como fonte de informação televisão, panfletos, os enfermeiros da ESF, comunicados do Ministério da Saúde e na própria convivência com outras pessoas.

\footnotetext{
Foi é panfletos, televisão, é email que eles ficam enviando pra gente direto. (T1) Através das informações do Ministério e dos enfermeiros daqui. (T3)

"Uai" a gente vê falando, tem as campanhas na televisão, tem os panfletos, tudo a gente fica sabendo, a gente sai e escuta as pessoas comunicando. (A5)

Na televisão e aqui mesmo no posto. (A4)
}

\section{DISCUSSÃO}

O conhecimento dos profissionais sobre a H1N1 apresenta-se superficial. Há diferenças do conteúdo dos relatos entre as diferentes categorias pesquisadas. Os enfermeiros, pela sua formação, mostraram ter maior conhecimento sobre a doença, enquanto a categoria de técnicos em enfermagem 
e agentes comunitários de saúde, um conhecimento mais restrito, que não abrange todas as questões referentes à doença e a vacina.

Diante do cenário atual, levando em consideração a pandemia de Influenza A H1N1 ocorrida em 2009 e o conhecimento sobre o vírus, o Ministério da Saúde preconizou ações voltadas para a Atenção Primária à Saúde (APS), considerando que a APS age no âmbito individual e coletivo com ações de promoção e proteção da saúde através do trabalho em equipe, dirigida à população ao qual assume responsabilidade, devendo, portanto, os profissionais serem dotados de conhecimento sobre a Influenza A H1N1 para realização de tais ações (BRASIL, 2006).

A falta de conhecimento dos profissionais de nível médio pode levar à dificuldade do trabalho da equipe, pois de acordo com o Ministério da Saúde, o sucesso e os resultados positivos das Equipes de Estratégia de Saúde da família, depende essencialmente do perfil e da atuação dos profissionais envolvidos. Os profissionais que possuem conteúdo insuficiente sobre a Gripe A e a vacina são os que estão em maior contato com a população, principalmente os ACS, que funcionam como um elo de comunicação entre a comunidade e a ESF, na medida em que se estabelece um vínculo com a mesma (SANTANA et al., 2009; BRASIL, 2007).

No primeiro momento, quando perguntados sobre o que eles sabiam sobre a Gripe A H1N1 e a vacina, os profissionais entrevistados, destacaram a doença principalmente na sua forma de transmissão, sendo possível apreender que a representação da doença para os profissionais é de caráter abstrato, pois os profissionais da ESF pesquisada não tiveram contato direto com casos de infecção por H1N1, logo o conteúdo científico que lhes foi transmitido não foi aplicado na prática, ficando apenas as informações com maior destaque na época.

O Ministério da Saúde (2009) realizou muitas campanhas de divulgação demonstrando os métodos preventivos e sua importância contra a Gripe A. As práticas preventivas são: lavar as mãos frequentemente com água e sabão, especialmente depois de tossir ou espirrar, cobrir o nariz e a boca com papéis descartáveis quando espirrar e tossir, não compartilhar objetos de uso pessoal, evitar ambientes aglomerados e fechados. Percebe-se que os profissionais conhecem as atitudes mínimas preventivas para a Gripe A, o que sugere que as campanhas foram efetivas.

Destaca-se que um técnico e um ACS confundiram a gripe com outras doenças e relataram formas de prevenção errôneas e equivocadas. Entre os relatos evidencia-se a transmissão por meio de picada de algum inseto, como acontece em doenças como dengue, febre amarela, leishmaniose e doença de Chagas. A relação sexual e contato com sangue também foi destacada como forma de transmissão da doença, ocorrida em doenças como AIDS e hepatite B.

A vacina para a Gripe A H1N1 se constitui também como um meio de prevenção, contudo, não foi citada pela maioria dos profissionais. A vacina confere proteção de até $90 \%$ e tem como objetivo 
reduzir a ocorrência de casos graves e óbitos, sendo, portanto, indicada para as pessoas de maior risco, que são crianças de seis meses a dois anos incompletos, gestantes, puérperas, indivíduos com mais de 60 anos, portadores de doenças crônicas, povos indígenas e profissionais de saúde. Atualmente a vacina encontra-se disponível, e na Campanha Nacional de Vacinação Contra Influenza ela é incluída (BRASIL, 2013).

Os profissionais conhecem os principais grupos de risco, se esquecendo, porém dos portadores de doenças crônicas e povos indígenas. O conhecimento apresentado pelos profissionais nesse estudo, pode ser explicado pelo fato de a pesquisa ter sido realizada no período da Campanha Nacional de Vacinação Contra Influenza e todos os profissionais haviam sido capacitados.

Quando perguntados sobre a ocorrência de mitos sobre a vacina, a categoria de enfermeiros e técnicos disse não saber ou que não existe. Já a categoria dos ACS, que são profissionais que possuem um contato mais próximo com a população, relatou a ocorrência de mitos, sobretudo os efeitos colaterais como motivo para não adesão à vacina. A questão dos eventos adversos também foi encontrado nos estudos de Gomes et al. (2012) e Barbosa et al. (2013), em que foram avaliados os motivos entre idosos e gestantes para a não adesão à vacina para Influenza Sazonal e Influenza A H1N1, respectivamente.

Os efeitos colaterais mais citados foram febre e dor no corpo. Outros fizeram referência a sintomas clássicos de gripe como reações adversas da vacina, fato que é decorrente do período em que a campanha de vacinação é realizada, em meses mais chuvosos e os indivíduos podem estar com o vírus incubado, diminuindo assim a eficácia da vacina, o que gera confusão dos sintomas da doença já em curso com as reações adversas da vacina (ARAÚJO et al., 2007).

É importante salientar que nenhuma vacina é livre de desencadear alguma reação adversa, porém os riscos de complicações decorrentes das doenças são maiores que as causadas pelas vacinas do calendário de imunizações (BRASIL, 2010).

A transmissão da doença pela ingestão de carne de porco é um mito que foi referido por parte de alguns profissionais. Salienta-se que não ocorre transmissão pela carne suína (MACHADO, 2009). Apesar de o vírus Gripe A H1N1 conter componentes genéticos de suínos, a carne de porco não oferece risco de disseminação da doença. Ainda que o animal estivesse infectado, o consumo não representaria risco para a contaminação de seres humanos desde que realizado o cozimento a $70{ }^{\circ} \mathrm{C}$ (BRASIL, 2009).

Verificou-se informações divergentes sobre a administração da vacina em pessoas que possuam alergia a ovo. Segundo o Ministério da Saúde (2013), a vacina é contra-indicada apenas para indivíduos com história de alergia grave a ovo, nas outras situações, pode ser administrada. 
As informações sobre a Gripe A H1N1 e a vacina são correlacionadas com os meios pelos quais elas são obtidas. Os enfermeiros apontam como fonte de informações o Ministério da Saúde, que se preocupou durante a pandemia em divulgar informações consistentes sobre a emergência do novo vírus e tranquilizar a população e nos dias atuais busca a vigilância, prevenção e controle nos casos de infecção pelo vírus H1N1. Os técnicos e ACS em geral reportam como fonte de informação a mídia, os enfermeiros e o convívio social.

É importante destacar que as informações errôneas apresentadas pelos técnicos em enfermagem e ACS podem ter influência com a cobertura midiática da pandemia de 2009. Estudos apontam que as coberturas feitas pela mídia davam destaque para a magnitude e alastramento da doença e que preocupados mais com a audiência, veicularam notícias que aumentaram a ansiedade da população, criando um clima de alarme e pânico. A mídia também colocou a prova as medidas adotadas pelas autoridades sanitárias o que gerou um clima de incerteza e insegurança na população, dando espaço para a divulgação de materiais na internet de cunho inadequado e incoerente com a realidade (MEDEIROS, MASSARANI, 2011; GOMES, FERRAZ, 2012).

Em estudo realizado com alunos do ensino médio sobre representações sociais de saúde, doença e dengue no período do ápice da pandemia foi possível compreender que as crianças também incorporaram as informações veiculadas na mídia e que a grande quantidade de informações acabou causando confusão, impedindo que as crianças fossem capazes de diferenciar a gripe suína da dengue, criando representações que, em vez de separar, associam as doenças (SZUKALA, 2010).

Com a compreensão de que os profissionais associam as representações, é importante que o enfermeiro, enquanto promotor de informações para a equipe da ESF, e visto como fonte e referência na obtenção de informações por parte dos técnicos e ACS pense sobre o conhecimento da equipe sobre a Gripe A H1N1. É preciso levar em consideração as informações que foram veiculadas pela mídia, no cotidiano dos profissionais e na realidade do local onde vivem. Torna-se importante pensar em estratégias de informação e educação diferenciadas para os profissionais, a fim de sanar dúvidas e equívocos e promover um aprendizado útil e eficaz.

O enfermeiro deve buscar a educação permanente como alternativa para preencher as lacunas do conhecimento identificadas, contribuindo assim para a transformação das práticas profissionais e da organização do trabalho. Na ESF, a educação permanente constitui-se como um instrumento essencial na capacitação e qualificação dos profissionais, buscando as lacunas de conhecimentos e atitudes que são parte da estrutura explicativa dos problemas identificados no cotidiano dos serviços e dando subsídios para que eles possam entender e atender às necessidades de saúde da população, contribuir na organização dos serviços e na formação dos profissionais da área de saúde (BRASIL, 2007) 


\section{CONSIDERAÇÕES FINAIS}

Observou-se que os enfermeiros da unidade conhecem as principais informações e orientações relacionadas à Influenza A (H1N1). Entretanto, as categorias profissionais de agente comunitário de saúde e técnico em enfermagem demonstraram através de seus relatos estarem pouco informados ou sem nenhuma informação sobre a Gripe A H1N1 e a vacina.

Embora haja um grande e notável empenho por parte do poder público para a divulgação de conhecimentos básicos em relação a esta doença, existem profissionais que não compreendem estas informações, uma vez que na análise das respostas percebemos que existem várias pessoas que confundem informações ou realmente não tem conhecimento delas.

Acredita-se que a educação permanente se constitui uma poderosa ferramenta para transmitir as informações básicas relacionadas à Influenza A (H1N1) aos profissionais que não compreendem corretamente as orientações preconizadas pelo Ministério da Saúde. O enfermeiro assume um papel chave nesse contexto, visto que é referido pelos ACS e técnicos de enfermagem como fonte de informações.

O ACS é a categoria que inspira maior preocupação, pois apresentou um conhecimento bastante restrito. Esse profissional mantém uma estreita ligação com a população e é importante que tenham conhecimento adequado para dar as orientações de forma correta para a população.

Sugere-se a realização de outras pesquisas nessa área que possam vir a acrescentar ou ampliar os resultados encontrados neste estudo, com outros profissionais. Devido à escassez de estudos sobre o tema é desejável que novas pesquisas sejam desenvolvidas com vista a promover ampla discussão, objetivando analisar o conhecimento dos profissionais de saúde e promovendo a melhoria da assistência. 


\section{REFERÊNCIAS}

ARAÚJO, T. M. E. Vacina contra Influenza: conhecimentos, atitudes e práticas de idosos em Teresina. Rev Bras Enferm, v. 60, n. 4, p. 439-443, 2007.

BARBOSA, T. L. A. et al. Motivos que levaram as gestantes a não se vacinarem contra H1N1. Ciência \& Saúde Coletiva. v. 18, n. 6, p. 3689-3696.

BELLEI, N.; MELCHIOR, T. B. H1N1: pandemia e perspectiva atual. J Bras Patol Med Lab, v.47, n.6, p. 611-617, 2011.

BRASIL. Ministério da Saúde (MS). Protocolo de Vigilância Epidemiológica de Eventos Adversos Pós Vacinação. Estratégia de Vacinação contra o Vírus Influenza Pandêmico (H1N1). 2010.

BRASIL, Ministério da Saúde (MS), Secretaria de Vigilância em Saúde, Programa Nacional de Imunizações. Informe Técnico: Campanha Nacional de Vacinação contra a Influenza, 2013.

BRASIL. Ministério da Saúde (MS). Portaria GM/MS n.1.996, de 20 de agosto de 2007. Dispõe sobre as diretrizes para a implementação da Política Nacional de Educação Permanente em Saúde e dá outras providências. Diário Oficial da União, n.162, 2007.

BRASIL. Ministério da Saúde (MS). Secretaria de Atenção à Saúde. Departamento de Atenção Básica. Política Nacional de Atenção Básica. 2006.

BRASIL, Ministério da Saúde (MS). Secretaria de Vigilância em Saúde. Gabinete Permanente de Emergências de Saúde Pública. Emergência de Saúde Pública de Importância Internacional ESPII: INFLUENZA A(H1N1), Protocolo de Notificação e Investigação. 2009.

BRASIL. Ministério da Saúde (MS). Avaliação da implementação do Programa Saúde da Família em dez grandes centros urbanos. Série C. Projetos, Programas e Relatórios. 2002.

BRASIL. Conselho Nacional de Secretários de Saúde. Atenção Primária e Promoção da Saúde / Conselho Nacional de Secretários de Saúde. - Brasília: CONASS, 2007. Disponível em: http://bvsms.saude.gov.br/bvs/publicacoes/colec_progestores_livro8.pdf. Acesso em: 02/06/2013.

BRASIL. Ministério da Saúde (MS). Secretaria de Vigilância em Saúde. Influenza pandêmica (H1N1) 2009 - Análise da situação epidemiológica e da resposta no ano de 2009. Boletim Eletrônico Epidemiológico, ano 10, n.1, 2010.

BRASIL. Conselho Nacional de Secretários de Saúde. Atenção Primária e Promoção da Saúde / Conselho Nacional de Secretários de Saúde. - Brasília-DF: CONASS, 2011. Brasília, 2011. $1^{\text {a }}$ ed. Volume 3. Coleção para entender a gestão do sus. Disponível em http://bvsms.saude.gov.br/bvs/publicacoes/para_entender_gestao_sus_v.3.pdf acesso em 11/06/2013

BRUM, A. V. et al. Perfil dos pacientes internados no Hospital São José do Avaí com suspeita de gripe A H1N1. Rev Bras Clin Med, v.9, n.3, p.185-188, 2011.

FONTANELLA, B. J. B.; RICAS, J.; TURATO, E. R. Amostragem por saturação em pesquisas qualitativas em saúde: contribuições teóricas. Cad. Saúde Pública, v.24, n.1, p.17-27, 2008.

GIL, A. C. Como elaborar projetos de pesquisa. 4a ed. São Paulo: Atlas, 2002. 
GOMES, L. M. X. et al. Motivos que levaram os idosos a não se vacinarem contra a influenza sazonal. R. pesq.: cuid. fundam. Online, v.4, n.3, p. 2561-2569, 2012.

GOMES, I. M. A. M.; FERRAZ, L. M. R. Ameaça e controle da gripe A(H1N1): uma análise discursiva de Veja, IstoÉ e Época. Saúde soc. v.21, n.2, Abr./Jun, 2012.

MACHADO, A. A. Infecção pelo vírus Influenza A (H1N1) de origem suína: como reconhecer, diagnosticar e prevenir. J Bras Pneumol, v.35, n.5, p.464-469, 2009.

MARCONI, M. A; LAKATOS, E. M. Técnicas de pesquisa. $6^{\text {a }}$ ed., Atlas, 2007.

MEDEIROS, F. N. S.; MASSARANI, L. A cobertura da gripe A (H1N1) 2009 pelo Fantástico. Intercom - Revista Brasileira de Ciências da Comunicação, v.34, n.1, p. 41-59, 2011.

MINAYO, M. C. S. O desafio do conhecimento: pesquisa qualitativa em saúde. $10^{\text {a }}$ ed., HucitecAbrasco; 2007.

OLIVEIRA, N. A. S.; IGUTI, A. M. O vírus Influenza H1N1 e os trabalhadores da suinocultura: uma revisão. Rev. bras. saúde ocup. v. 35, n. 122, p. 353-361, 2010.

PASTORE, A. P. W.; PRATES, C. S.; GUTIERREZ, L. L. P. Conhecimento sobre a influenza A (H1N1) pdm09 entre indivíduos vacinados no Centro Universitário Metodista IPA, Porto Alegre, Rio Grande do Sul. Scientia Médica, v.22, n.4, p. 197-202, 2012.

SANTANA, J. C. B.; VASCONCELOS, A. L.; MARTINS, C. V.; BARROS, J. V.; SOARES, J. M.; DUTRA, B. S. Agente comunitário de saúde: percepções na estratégia de saúde da família. Cogitare Enferm, v.14, n.4, p.645-52, 2009.

SENNA et al.; Emergência do vírus influenza A-H1N1 no Brasil: a propósito do primeiro caso humano em Minas Gerais. Rev Med Minas Gerais, v.19, n.02, p. 173-176, 2009.

SZUKALA, C. M. Representação social de saúde, doença e dengue para alunos do ensino fundamental. 2010. 103p. Dissertação (Mestrado em Psicologia) - Universidade Católica Dom Bosco, Campo. Grande, 2010. 